\title{
LORETA Functional Imaging in Antipsychotic-Naive and Olanzapine-, Clozapine- and Risperidone-Treated Patients with Schizophrenia
}

\author{
Barbora Tislerova ${ }^{\mathrm{a}-\mathrm{c}}$ Martin Brunovsky ${ }^{\mathrm{a}-\mathrm{c}}$ Jiri Horacek $^{\mathrm{a}-\mathrm{c}}$ Tomas Novak $^{\mathrm{a}-\mathrm{c}}$ \\ Miloslav Kopecek ${ }^{\mathrm{a}-\mathrm{c}}$ Pavel Mohr ${ }^{\mathrm{a}-\mathrm{c}}$ Vladimír Krajca $^{\mathrm{d}}$ \\ a 3 rd Faculty of Medicine, Charles University, ${ }^{b}$ Prague Psychiatric Center, ${ }^{c}$ Center of Neuropsychiatric Studies and \\ ${ }^{\mathrm{d} D e p a r t m e n t}$ of Neurology, Faculty Hospital Bulovka, Prague, Czech Republic
}

\section{Key Words}

Schizophrenia $\cdot$ Low-resolution brain electromagnetic tomography • Quantitative electroencephalography • Atypical antipsychotics · Anterior cingulum

\begin{abstract}
The aim of our study was to detect changes in the distribution of electrical brain activity in schizophrenic patients who were antipsychotic naive and those who received treatment with clozapine, olanzapine or risperidone. We included 41 subjects with schizophrenia (antipsychotic naive $=11$; clozapine $=8$; olanzapine $=10$; risperidone $=12$ ) and 20 healthy controls. Low-resolution brain electromagnetic tomography was computed from 19-channel electroencephalography for the frequency bands delta, theta, alpha-1, alpha-2, beta- 1 , beta- 2 and beta- 3 . We compared antipsychotic-naive subjects with healthy controls and medicated patients. (1) Comparing antipsychotic-naive subjects and controls we found a general increase in the slow delta and theta frequencies over the fronto-temporo-occipital cortex, particularly in the temporolimbic structures, an increase in alpha- 1 and alpha- 2 in the temporal cortex and an increase in beta- 1 and beta- 2 in the temporo-occipital and posterior limbic structures. (2) Comparing patients who received clozapine and
\end{abstract}

those who were antipsychotic naive, we found an increase in delta and theta frequencies in the anterior cingulate and medial frontal cortex, and a decrease in alpha- 1 and beta- 2 in the occipital structures. (3) Comparing patients taking olanzapine with those who were antipsychotic naive, there was an increase in theta frequencies in the anterior cingulum, a decrease in alpha-1, beta- 2 and beta- 3 in the occipital cortex and posterior limbic structures, and a decrease in beta- 3 in the frontotemporal cortex and anterior cingulum. (4) In patients taking risperidone, we found no significant changes from those who were antipsychotic naive. Our results in antipsychotic-naive patients are in agreement with existing functional findings. Changes in those taking clozapine and olanzapine versus those who were antipsychotic naive suggest a compensatory mechanism in the neurobiological substrate for schizophrenia. The lack of difference in risperidone patients versus antipsychotic-naive subjects may relate to risperidone's different pharmacodynamic mechanism.

Copyright $\odot 2008$ S. Karger AG, Basel

This paper was presented as a poster at the 14th International Pharmaco-EEG Society Training Course and Symposium on Awaji Island, Japan, September 6-10, 2006.

\section{KARGER}

Fax +4161306 1234 E-Mail karger@karger.ch www.karger.com

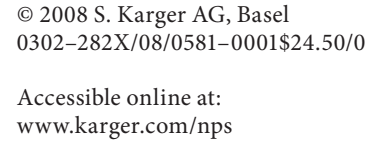

Dr. Barbora Tislerova

Prague Psychiatric Center

Ustavni 91

CZ-181 03 Praha 8 (Czech Republic)

Tel. +420 266003 381/310, Fax +420 266003 366, E-Mail tislerova@pcp.lf3.cuni.cz 


\section{Introduction}

Research on electrical brain activity in schizophrenic patients has developed over the last few years, particularly by means of quantitative electroencephalography (qEEG) methods. Low-resolution brain electromagnetic tomography (LORETA) represents a new approach to addressing the limited spatial resolution of EEG and, moreover, permits truly 3-dimensional tomography of electrical brain activity (current density) $[1,2]$. Previous LORETA studies in unmedicated patients with schizophrenia have mainly detected an increase in slow frequencies [3-5], probably reflecting cortical hypoactivation.

Progress in the pharmacology of antipsychotics represents one of the most important successes of applied neuroscience. While antipsychotic drugs provide a basic therapeutic tool for the treatment of schizophrenia and other psychotic conditions, their effectiveness is associated with a series of unresolved questions. It is not clear, for example, which of the neurobiological mechanisms (beyond $\mathrm{D}_{2}$ receptor blocking) is the final therapeutic target responsible for the beneficial effect on distorted information processing in schizophrenia, and for subsequent elimination or reduction of the psychotic symptoms [6].

Olanzapine and clozapine are atypical antipsychotics of the thienobenzodiazepine class. They have similarities in molecular structure and receptor profile. Both of them produce changes that can be observed on visual inspection and on quantitative analysis of EEG [7]. qEEG changes related to various atypical antipsychotic drugs have been reported in recent years [5, 8-12]. In clozapine- and olanzapine-induced qEEG changes, an increase in slow frequency bands was found, both in routinely treated patients $[8,9]$ and in healthy volunteers after a single dose $[10,11]$. Risperidone represents the class called serotonindopamine antagonists. On visual evaluation of EEG, risperidone produces fewer changes than clozapine and olanzapine [7]. However, as yet there are no studies comparing the effect of atypical antipsychotics in schizophrenic patients by qEEG analysis.

To date no study focusing on the changes in the 3-dimensional distribution of electrical brain activity in patients treated with different types of atypical antipsychotics has been published. The aim of our study was to detect the changes in the distribution of electrical brain activity by the use of LORETA in patients with schizophrenia who were antipsychotic naive and those who received treatment with clozapine, olanzapine or risperidone.
With regard to previous studies, we hypothesized that antipsychotic-naive patients will exhibit a global increase in slow frequencies, particularly in the frontal and temporolimbic structures. In medicated patients, we expected an increase in slow frequencies and to see the effect of atypical antipsychotics on regional distribution of current densities in the frontal structures.

\section{Methods}

\section{Participants}

In our study we included 41 right-handed inpatients (22 males, 19 females; median age 26.0 years, interquartile range $22.0-32.0$ ) who were diagnosed as having schizophrenia or an acute psychotic episode (F20.0 or F23.1 according to ICD-10 classification [13]) and who were treated in the Prague Psychiatric Center. Patients experiencing their first psychotic episode who had never used any antipsychotic medication were included in the antipsychotic-naive group. For the rest of the patients, the main inclusion criterion was that they had been receiving an antipsychotic in monotherapy. All of these patients used only one type of atypical antipsychotic and did not use any other psychotropic medication (e.g. benzodiazepines, antidepressants, anticholinergics or mood stabilizers). The minimal length of the stabile monotherapy was 1 month. We divided the medicated patients into 3 groups according to the drug they used (clozapine, olanzapine and risperidone). Patients who had pathological changes in EEG patterns were excluded, as were patients who had a comorbidity (e.g. drug abuse, drug addiction, epilepsy or a history of head trauma). The data were collected over the period of 4 years between 2003 and 2006.

The control group included 20 right-handed healthy subjects (10 males, 10 females; median age 26.0 years, interquartile range 25.0-28.0). The inclusion criteria were right-handedness, a negative psychiatric family history, matching age and EEG patterns without pathological changes.

The Prague Psychiatric Center Institutional Review Board reviewed and approved this study, and a written informed consent to participate in the research was obtained from all subjects. The study was carried out in accordance with the latest version of the Declaration of Helsinki.

EEG Recording and LORETA Analysis

The 19 surface electrodes were placed according to the international 10/20 system (Fp1, Fp2, F7, F3, Fz, F4, F8, T3, C3, Cz, C4, T4, T5, P3, Pz, P4, T6, O1 and O2), with all electrode impedances kept below $5 \mathrm{k} \Omega$. We used the Brainscope digital amplifier system (Unimedis, Prague, Czech Republic), with $\mathrm{Cz}$ as a reference electrode. The EEG recording system acquired the data with a 16-bit depth and a $7.63 \mathrm{nV} /$ bit resolution (i.e. approx. $130 \mathrm{bit} / \mu \mathrm{V}$ ) with the dynamic range of $\pm 250 \mu \mathrm{V}$. The data sampling rate was 250 $\mathrm{Hz}$, and the acquired signals were filtered with a band-pass filter of $0.15-70 \mathrm{~Hz}$ after the sampling. The EEG data (30 min in duration) were recorded in a sound-attenuated room that had subdued lighting where the patients lay in a semirecumbent position, with their eyes closed but in a maximally alert state. During the recording, the alertness was controlled. If patterns of drowsiness ap- 
Table 1. Demographic and clinical data

\begin{tabular}{|c|c|c|c|c|c|c|}
\hline & $\begin{array}{l}\text { Healthy controls } \\
(\mathrm{n}=20)\end{array}$ & $\begin{array}{l}\text { Antipsychotic } \\
\text { naive }(\mathrm{n}=11)\end{array}$ & $\begin{array}{l}\text { Clozapine } \\
(\mathrm{n}=8)\end{array}$ & $\begin{array}{l}\text { Olanzapine } \\
(\mathrm{n}=10)\end{array}$ & $\begin{array}{l}\text { Risperidone } \\
(\mathrm{n}=12)\end{array}$ & $\mathrm{p}$ value \\
\hline Sex (male/female) & $10 / 10$ & $7 / 4$ & $2 / 6$ & $6 / 4$ & $7 / 5$ & n.s. ${ }^{\mathrm{a}}$ \\
\hline Age, years & $26(25-28)$ & $27(23.5-31)$ & $26(25.5-30.5)$ & $24.5(19-30)$ & $26(23.5-34)$ & n.s. ${ }^{b}$ \\
\hline Length of treatment, months & - & 0 & $1.5(1-15)$ & $1(1-2)$ & $1.5(1-2)$ & n.s. ${ }^{b, c}$ \\
\hline Duration of illness, months & - & $2(1-4.5)$ & $24(12-39)^{*}$ & $7.5(2-12)$ & $4.5(2-5)$ & $<0.01^{\mathrm{b}}$ \\
\hline Dose of the drug, mg/day & - & 0 & $312(231-425)$ & $20(15-20)$ & $4(4-4.2)$ & n.a. \\
\hline CGI & - & $5(5-6)^{*}$ & $4(3.75-4)$ & $4(3.25-4)$ & $3.5(3-4)$ & $<0.001^{\mathrm{b}}$ \\
\hline Diagnoses (F20.0/F23.1) & - & $3 / 8^{*}$ & $7 / 1$ & $7 / 3$ & $6 / 6$ & $<0.05^{\mathrm{a}}$ \\
\hline Education, years & $16(15-18)$ & $14(12-16)$ & $13.5(12-17)$ & $12(12-16.5)$ & $12(11-16.5)$ & n.s. ${ }^{b}$ \\
\hline
\end{tabular}

Data are shown as median and interquartile range. n.s. = Not significant; n.a. = not applicable; CGI = Clinical Global Impression Scale. ${ }^{*} \mathrm{p}<0.05$ : significant difference after post-hoc analysis.

${ }^{\mathrm{a}} \chi^{2}$ test. ${ }^{\mathrm{b}}$ Kruskal-Wallis test. ${ }^{\mathrm{c}}$ Only medicated groups were included.

peared in the EEG, the subjects were aroused by acoustic stimulation. Before analysis of the data, artifact detection was performed visually, with the exclusion of all EEG segments containing obvious eye and head movements, muscle artifacts or a decrease in alertness. After recomputation to the average reference, spectral analysis was performed for at least $30 \mathrm{~s}$ of artifact-free data. The cross-spectra were averaged across the $50 \%$ overlapping windows, which yielded 7 frequency bands: delta $(1.5-6 \mathrm{~Hz})$, theta $(6.5-$ $8 \mathrm{~Hz})$, alpha-1 $(8.5-10 \mathrm{~Hz})$, alpha-2 $(10.5-12 \mathrm{~Hz})$, beta-1 $(12.5-18$ $\mathrm{Hz})$, beta-2 $(18.5-21 \mathrm{~Hz})$ and beta-3 $(21.5-30 \mathrm{~Hz})[14]$.

Subsequently, LORETA was used to estimate the 3-dimensional intracerebral current density distribution $[1,2]$. LORETA computes the current density for 2,394 voxels in the brain as a linear, weighted sum of the scalp electrical potentials. A 3 shell spherical head model was restricted to the Talairach atlas. LORETA was restricted to the cortical gray matter and hippocampus following the Talairach probability atlas at a $7-\mathrm{mm}$ spatial resolution. Since EEG spectral frequency bands are known to reflect different functions, for each subject 7 time-averaged LORETA images (in the delta, theta, alpha-1, alpha-2, beta-1, beta2 and beta- 3 frequency bands) were computed and used for further analysis [4].

\section{Statistical Analysis}

The demographic and clinical characteristics of the 4 patient groups and the group of healthy controls are reported as medians with interquartile ranges. Differences between the groups were assessed by $x^{2}$ tests and by the Kruskal-Wallis 1-way analysis of variance test. Once a significant difference was identified using the Kruskal-Wallis test $(\mathrm{p}<0.05)$, the Wilcoxon 2 -sample ranked sum test was applied for comparing any 2 groups, with a Bonferroni correction to adjust the $\mathrm{p}$ values for multiple comparisons. Statistical analysis was carried out using Statistica 7.0 (Statsoft Inc.).

Statistical comparisons of LORETA-estimated current density were performed between the following groups of subjects: (1) antipsychotic-naive patients versus healthy control subjects; (2) patients taking clozapine versus antipsychotic-naive subjects; (3) pa- tients taking olanzapine versus antipsychotic-naive subjects; (4) patients taking risperidone versus antipsychotic-naive subjects.

The localization of the differences in activity between the groups was assessed by voxel-by-voxel nonpaired t tests of the LORETA images, based on the log-transformed power of the estimated electric current density, which resulted in t statistic 3-dimensional images. In these images, cortical voxels of statistically significant differences were identified by a nonparametric approach using a randomization strategy that determined the critical probability threshold values for the actually observed statistic with corrections for multiple testing [15].

To visualize the global distributions of the t test differences, for each band we computed the location of the mean center of gravity of all voxels with positive and negative $t$ values. To correct for multiple comparisons, a nonparametric single-threshold test was applied on the basis of the theory of randomization and on permutation tests [15]. The omnibus null hypothesis of no activation anywhere in the brain was rejected if at least $1 \mathrm{t}$ value (i.e. voxel, $t_{\text {MAX }}$ ) was above the critical threshold for $p=0.05$, determined by 5,000 randomizations [16].

\section{Results}

The patients and controls did not differ significantly in sex, age, or in their level of education. No significant difference between the patient groups was detected in the length of the treatment or in clinical evaluation (using the Clinical Global Impression scale). The length of the illness was significantly longer in the clozapine group, since clozapine is indicated in patients with schizophrenia who do not respond to previous treatment. The Clinical Global Impression scale was significantly higher in the antipsychotic-naive group, as in these patients treatment had not yet been started. The 
Table 2. Statistically significant results $(\mathrm{p}<0.01)$ from the comparison of the antipsychotic-naive group with healthy controls

\begin{tabular}{|c|c|c|c|c|c|c|c|}
\hline \multirow[t]{3}{*}{ Cortical area } & \multirow[t]{3}{*}{ Brodmann area } & \multicolumn{6}{|c|}{ Number of voxels } \\
\hline & & \multicolumn{2}{|c|}{$\begin{array}{l}\text { delta band } \\
\text { increase }\end{array}$} & \multicolumn{2}{|c|}{$\begin{array}{l}\text { theta band } \\
\text { increase }\end{array}$} & \multicolumn{2}{|c|}{$\begin{array}{l}\text { alpha-1 band } \\
\text { increase }\end{array}$} \\
\hline & & $\mathrm{L}$ & $\mathrm{R}$ & $\mathrm{L}$ & $\mathrm{R}$ & $\mathrm{L}$ & $\mathrm{R}$ \\
\hline Anterior cingulate & $10,24,25,32$ & 16 & 16 & & & & \\
\hline Precentral gyrus & $4,6,44$ & 13 & 39 & & & & \\
\hline Inferior frontal gyrus & $9,10,11,13,44,45,46,47$ & 70 & 82 & & 63 & 1 & 37 \\
\hline Medial frontal gyrus & $9,10,11,25$ & 37 & 41 & & & & \\
\hline Middle frontal gyrus & $9,10,11,43,46,47$ & 77 & 89 & & 14 & & 13 \\
\hline Superior frontal gyrus & $8,9,10,11$ & 54 & 61 & & 2 & & 6 \\
\hline Middle temporal gyrus & $19,20,21,22,37,38,39$ & 90 & 97 & 11 & 81 & 8 & 19 \\
\hline Inferior temporal gyrus & $19,20,21,37$ & 37 & 39 & 6 & 30 & 4 & 4 \\
\hline Superior temporal gyrus & $13,21,22,38,39,41,42$ & 82 & 96 & 19 & 45 & 17 & 19 \\
\hline Transverse temporal gyrus & 41,42 & 3 & 3 & & & & \\
\hline Insula & 13 & 37 & 36 & & 14 & & 2 \\
\hline Middle occipital gyrus & $18,19,37$ & 26 & 22 & 19 & 21 & & \\
\hline Inferior occipital gyrus & $17,18,19$ & 9 & 9 & 3 & 8 & & \\
\hline Superior occipital gyrus & 19 & 4 & 4 & 3 & 4 & & \\
\hline Uncus & $20,28,36,38$ & 21 & 21 & 21 & 21 & 3 & \\
\hline Fusiform gyrus, subgyral & $18,19,20,21,36,37$ & 58 & 52 & & 26 & 13 & 1 \\
\hline Parahippocampal gyrus & $27,28,30,34,35,36,37$ & 43 & 46 & 15 & 22 & & \\
\hline Cuneus, precuneus & $7,17,18,19,23,31$ & 49 & 49 & 7 & 5 & & \\
\hline Lingual gyrus & $17,18,19$ & 16 & 15 & & & & \\
\hline Postcentral gyrus & $1,3,40,43$ & 11 & 35 & & & & \\
\hline Posterior cingulate & 30,31 & 5 & 5 & & & & \\
\hline Inferior parietal lobule & $7,39,40$ & 9 & 55 & & & & \\
\hline$\underline{\text { Superior parietal lobule }}$ & 7 & & 11 & & & & \\
\hline Orbital, rectal gyrus & 11 & 18 & 15 & & & & \\
\hline Subcallosal gyrus & $13,25,34$ & 8 & 8 & & 3 & & \\
\hline Angular, supramarginal gyrus & 39,40 & 5 & 18 & & & & \\
\hline Extranuclear & 13,47 & 4 & 3 & & 3 & & \\
\hline Precentral gyrus & 6,44 & & & & 9 & & \\
\hline
\end{tabular}

number of patients with the diagnosis F23.1 was significantly higher in the antipsychotic-naive group since patients experiencing their first psychotic episode were included in this group. Detailed demographic and clinical data of the study subjects, including average doses of the drugs, are shown in table 1.

Comparing antipsychotic-naive subjects and healthy controls, we found a significant current density increase in the delta, theta, alpha-1, alpha-2, beta- 1 and beta- 2 frequency bands. We found a global current density increase in the delta frequency band over the whole cortex, with the maximum in the right temporolimbic structures. In the theta and alpha-1 bands we found an increase in the fronto-temporo-limbic structures. In the alpha- 2 band we found a significant current density increase in the right temporal cortex and an increase of beta- 1 and beta2 current densities in temporo-occipital and posterior limbic structures. Due to the increase in current densities in large brain regions at $\mathrm{p}<0.05$ (which was set for this study), we used a more conservative critical threshold ( $p<0.01$, after correction for multiple testing) to demonstrate the local maxima of differences between both groups (table 2, fig. 1). 


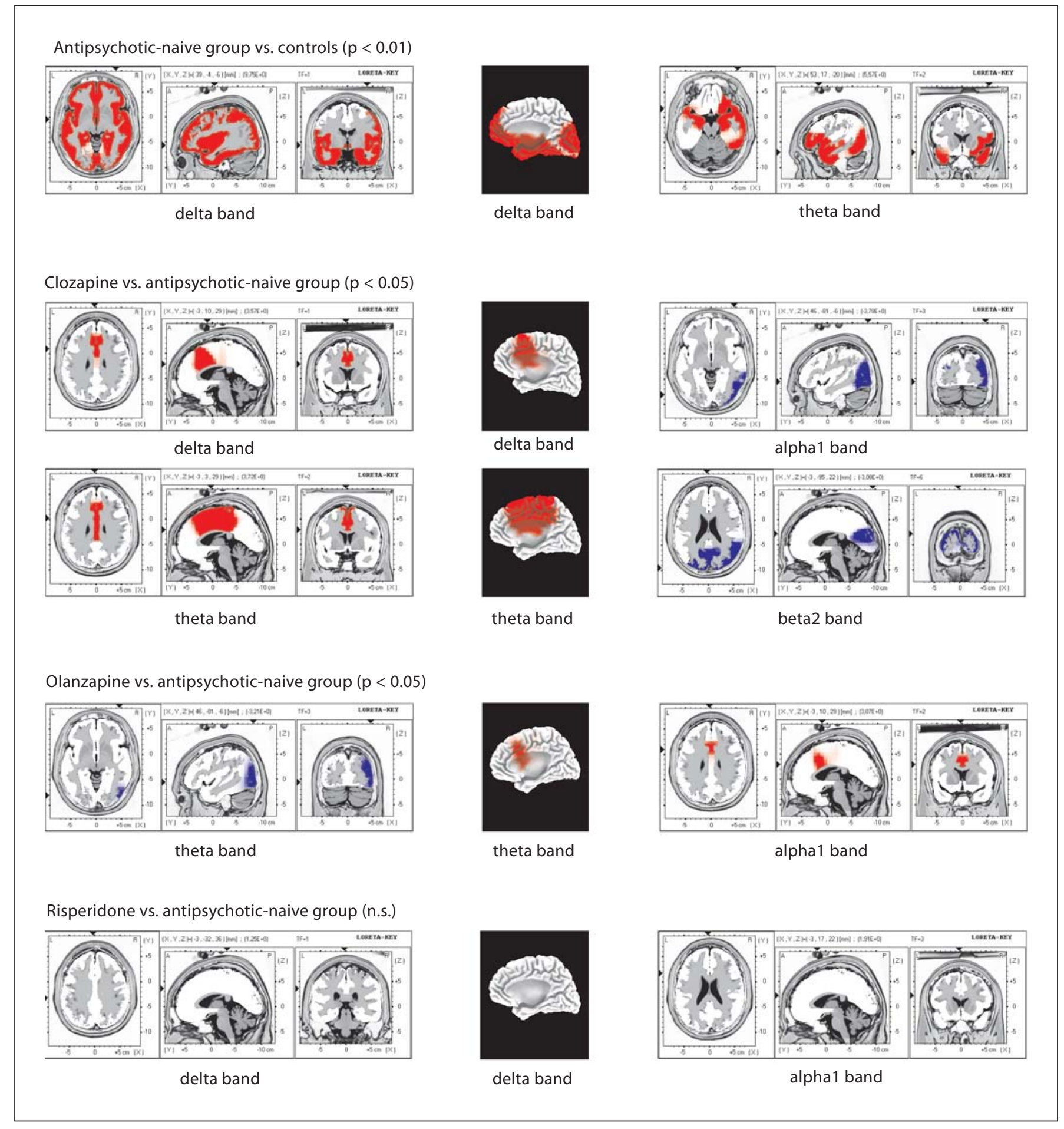

Fig. 1. Images of voxel-by-voxel nonpaired t statistics of brain regional electrical activity using LORETA for selected frequency bands. The results of 4 comparisons of marked subject groups are presented. Increases of current density are shown in red, decreases are in blue. Only voxels reaching the denoted statistical sig- nificance level are shown in color. Three orthogonal brain views in Talairach space are sliced through the region of the extreme $t$ value, given as $\mathrm{X}, \mathrm{Y}, \mathrm{Z}$ coordinates in Talairach space and graphically indicated by black triangles on the coordinate axes. n.s. $=$ No significant differences in the current density distribution. 
Table 3. Statistically significant results $(\mathrm{p}<0.05)$ from the comparison of patients taking clozapine with the antipsychotic-naive group

\begin{tabular}{|c|c|c|c|c|c|c|c|c|c|}
\hline \multirow[t]{3}{*}{ Cortical area } & \multirow[t]{3}{*}{ Brodmann area } & \multicolumn{8}{|c|}{ Number of voxels } \\
\hline & & \multicolumn{2}{|c|}{$\begin{array}{l}\text { delta band } \\
\text { increase }\end{array}$} & \multicolumn{2}{|c|}{$\begin{array}{l}\text { theta band } \\
\text { increase }\end{array}$} & \multicolumn{2}{|c|}{$\begin{array}{l}\text { alpha- } 1 \text { band } \\
\text { decrease }\end{array}$} & \multicolumn{2}{|c|}{$\begin{array}{l}\text { beta- } 2 \text { band } \\
\text { decrease }\end{array}$} \\
\hline & & $\mathrm{L}$ & $\mathrm{R}$ & $\mathrm{L}$ & $\mathrm{R}$ & $\mathrm{L}$ & $\mathrm{R}$ & $\mathrm{L}$ & $\mathrm{R}$ \\
\hline Anterior cingulate & $24,31,32,33$ & 9 & 8 & 6 & 6 & & & & \\
\hline Cingulate gyrus & $24,31,32$ & 15 & 17 & 46 & 46 & & & 1 & \\
\hline Paracentral lobule & $4,5,6,31$ & & & 10 & 10 & & & & \\
\hline Medial frontal gyrus & $6,8,9$ & 5 & 5 & 22 & 17 & & & & \\
\hline Superior frontal gyrus & 6,8 & 4 & 6 & 20 & 18 & & & & \\
\hline Fusiform gyrus, subgyral & 19,37 & & & & & & 5 & & 13 \\
\hline Parahippocampal gyrus & $19,27,30,35$ & & & & & & & 18 & 30 \\
\hline Cuneus & $17,18,19$ & & & & & 4 & 6 & 15 & 11 \\
\hline Precuneus & $19,23,24,30,31$ & & & 3 & 5 & & & 7 & 5 \\
\hline Middle occipital gyrus & $18,19,37$ & & & & & 12 & 21 & 14 & 21 \\
\hline Inferior occipital gyrus & $17,18,19$ & & & & & & & & 6 \\
\hline Superior occipital gyrus & 19 & & & & & 2 & 4 & 2 & 4 \\
\hline Middle temporal gyrus & $19,21,37,39$ & & & & & & 23 & & 32 \\
\hline Inferior temporal gyrus & $18,19,37$ & & & & & & 12 & & 6 \\
\hline Superior temporal gyrus & $13,22,39$ & & & & & & & & 14 \\
\hline Lingual gyrus & 18 & & & & & & 1 & & 1 \\
\hline Posterior cingulate & 30,31 & & & & & & & 4 & 1 \\
\hline Inferior parietal lobule & 40 & & & & & & & & 3 \\
\hline Angular, supramarginal gyrus & 39 & & & & & & 1 & & 8 \\
\hline
\end{tabular}

In the comparison of patients who received clozapine versus the antipsychotic-naive group, we found a significant current density increase in the delta and theta bands in the anterior cingulate and medial frontal cortex, and a significant current density decrease in alpha- 1 and beta- 2 in temporo-occipital structures. All voxels that reached the critical threshold of $\mathrm{p}<0.05$, after correction for multiple testing, are shown in table 3.

The olanzapine group differed from the antipsychotic-naive subjects in the theta band in the anterior cingulate and medial frontal cortex. A significant current density decrease was detected in the alpha-1, beta- 2 and beta3 bands in the occipital cortex and posterior limbic structures. A significant decrease in the beta-3 band was also observed in the anterior cingulate and frontotemporal cortex. All voxels that reached the critical threshold ( $\mathrm{p}<0.05$, after correction for multiple testing) are shown in table 4 .
Comparing the patients who received risperidone and the antipsychotic-naive group, we found no significant differences in the current density distribution.

\section{Discussion}

In this study, we investigated the differences in the distribution of brain electrical activity in schizophrenic patients who were antipsychotic naive and those who had received treatment with clozapine, olanzapine or risperidone.

The results of the comparison of the antipsychoticnaive group with the healthy controls are in partial agreement with other qEEG and functional neuroimaging reports in the literature $[3,4,17,18]$. An increase in current density in the delta and theta frequency bands in the frontal and temporolimbic-occipital cortex suggests decreased functional activity in frontal areas (hy- 
Table 4. Statistically significant results $(\mathrm{p}<0.05)$ from the comparison of patients taking olanzapine with the antipsychotic-naive group

\begin{tabular}{|c|c|c|c|c|c|c|c|c|c|}
\hline \multirow[t]{3}{*}{ Cortical area } & \multirow[t]{3}{*}{ Brodmann area } & \multicolumn{8}{|c|}{ Number of voxels } \\
\hline & & \multicolumn{2}{|c|}{$\begin{array}{l}\text { theta band } \\
\text { increase }\end{array}$} & \multicolumn{2}{|c|}{$\begin{array}{l}\text { alpha- } 1 \text { band } \\
\text { decrease }\end{array}$} & \multicolumn{2}{|c|}{$\begin{array}{l}\text { beta-2 band } \\
\text { decrease }\end{array}$} & \multicolumn{2}{|c|}{$\begin{array}{l}\text { beta- } 3 \text { band } \\
\text { decrease }\end{array}$} \\
\hline & & $\mathrm{L}$ & $\mathrm{R}$ & $\mathrm{L}$ & $\mathrm{R}$ & $\mathrm{L}$ & $\mathrm{R}$ & $\mathrm{L}$ & $\mathrm{R}$ \\
\hline Anterior cingulate & $24,31,32,33$ & 2 & 2 & & & & & 12 & 11 \\
\hline Cingulate gyrus & $24,31,32$ & 12 & 10 & & & 2 & 2 & 10 & 9 \\
\hline Medial frontal gyrus & $6,8,9,25$ & & & & & & & 10 & 7 \\
\hline Subcallosal gyrus & 25,34 & & & & & & & 3 & 2 \\
\hline Superior frontal gyrus & 6,8 & & & & & & & 2 & 5 \\
\hline Middle frontal gyrus & 8 & & & & & & & 2 & \\
\hline Parahippocampal gyrus & $19,27,30,35,36,37$ & & & & & 18 & 30 & 20 & 20 \\
\hline Fusiform gyrus, subgyral & $19,20,37$ & & & & & & & 11 & 6 \\
\hline Cuneus & $17,18,19$ & & & & & 24 & 17 & & \\
\hline Precuneus & $19,23,24,30,31$ & & & & & 23 & 24 & & \\
\hline Middle occipital gyrus & $18,19,37$ & & & & & 25 & 22 & & \\
\hline Inferior occipital gyrus & $17,18,19$ & & & & & 9 & 9 & & \\
\hline Superior occipital gyrus & 19 & & & & & 4 & 4 & & \\
\hline Middle temporal gyrus & $19,21,37,39$ & & & 19 & 39 & 16 & 35 & & \\
\hline Inferior temporal gyrus & $18,19,37$ & & & & 2 & 3 & 8 & & \\
\hline Superior temporal gyrus & $13,22,39$ & & & & & 2 & 22 & & 1 \\
\hline Lingual gyrus & 18 & & & & & 36 & 27 & 10 & 7 \\
\hline Posterior cingulate & 30,31 & & & & & 19 & 25 & & \\
\hline Inferior parietal lobule & 40 & & & & & 1 & 19 & & \\
\hline Angular, supramarginal gyrus & 39,40 & & & & & & 18 & & 1 \\
\hline
\end{tabular}

pofrontality) and global cortical hypofunction. This finding is congruent with the concept of glutamatergic dysfunction in schizophrenia, as evidenced by the reduced density of the prefrontal cortex pyramidal cell dendrites, glutamatergic synaptosomes and synaptophysine [19-21].

An increase in low band power (delta) activity has been repeatedly found in the vast majority of qEEG studies in which schizophrenic patients were compared to normal subjects. The results of a LORETA study [3] with 19 medication-free schizophrenic patients showed a general increase in delta activity over the whole cortex, particularly in the anterior cingulate gyrus and temporal lobe. Although the patients included in that study were medication free and not antipsychotic naive, our findings are in accordance with the result. Using LORETA, Pascual-Marqui et al. [4] found an anterior excess of delta activity, an anterior-inferior deficit of theta and alpha ac- tivity and a posterior-superior right-sided excess of beta1 , beta- 2 and beta- 3 frequency activity in 9 antipsychoticnaive patients experiencing their first episode of schizophrenia. Similarly, we found a frontal increase in current density in the delta band and an increase in the beta frequency band in posterior structures. However, our results differ in the theta and alpha bands. A possible explanation may be that the changes of activity in the alpha and theta frequency bands are a little more closely related to the status of vigilance, attention and relaxation than to the psychopathology itself.

Findings in functional brain imaging studies (using positron emission tomography and single-photon emission computed tomography) in patients with schizophrenia frequently show the same regional changes as we found in the distribution of electrical brain activity, particularly in the frontal cortex (hypofrontality) and in the temporolimbic regions $[17,18]$. 
In the comparison of the patients who received clozapine and olanzapine with the antipsychotic-naive group, we obtained similar results: an increase in slow frequencies in the anterior cingulate and the medial frontal cortex. These results are in accordance with anatomical and functional studies in schizophrenic patients, which consistently describe volume and metabolism changes in the anterior cingulate subsequent to atypical antipsychotic treatment $[8,9,22-24]$.

In another LORETA study [9] involving 25 chronically medicated patients with schizophrenia, there was an excess of delta and theta frequencies located in the right middle frontal gyrus, right inferior frontal gyrus and right insula, as well as the bilateral anterior cingulum. However, only 2 patients in this study used atypical antipsychotics, the others used conventional ones. Correlation of the clozapine-induced clinical qEEG changes with the clinical response was detected in another qEEG prospective, longitudinal study in 16 schizophrenic patients [8]. This found a significant increase in theta frequency in the electrodes over the frontocentral scalp area after 3 weeks of treatment with clozapine. These electrodes reflect activity from the frontal cortex, including the anterior cingulum.

Previous qEEG studies of antipsychotic drugs in healthy volunteers have shown a significant sedative effect compared to placebo $[5,10,11,25]$. A study of healthy subjects [11] found an increase in electrical activity in the theta and a decrease in the alpha- 2 and beta bands after a single dose of olanzapine. In another [25], there was an increase in delta power in healthy volunteers after a single dose of olanzapine, and a study in healthy men [10] found an increase in delta and theta frequencies and a decrease in alpha and beta frequencies after clozapine.

The role of the anterior cingulate cortex in the pathophysiology of schizophrenia was described in functional (positron emission tomography) [22, 23], volumetric [24, 26] and electrophysiological (LORETA) studies [27, 28]. A magnetic resonance imaging study [24] of 31 antipsychotic-naive schizophrenics found a positive correlation between an increased anterior cingulate volume and typical antipsychotic exposure over time (2-3 years later), while increased atypical antipsychotic exposure was correlated with a decreased anterior cingulate volume. Another magnetic resonance imaging study [26] found a correlation between an increased cingulate volume and typical antipsychotic exposure. A positron emission tomography study [22] reported that clozapine, but not haloperidol, normalizes anterior cingulate regional cerebral blood flow patterns in schizophrenia during a cognitive task. Another recent study [23] reported an increase in regional cerebral blood flow in the anterior cingulate and temporal cortex after a single dose of olanzapine in drug-free schizophrenic volunteers. Electrophysiological LORETA studies showed decreased activation in the anterior cingulate gyrus in subjects with schizophrenia $[27,28]$.

The absence of haloperidol or other conventional antipsychotic-treated groups represents a substantial limitation of our study. The reason for this is that to satisfy the main inclusion criterion, patients had be receiving an antipsychotic in monotherapy, and haloperidol monotherapy treatment is no longer involved in current routine treatment standards.

In the comparison of the patients who received risperidone with the antipsychotic-naive schizophrenia group, we found no significant changes, which may be related to its different mechanism of action. The substantial differences between clozapine and olanzapine, on the one hand, and risperidone, on the other, could be related to the mechanism of action of both classes of drug. Risperidone is characterized by a high selectivity of dopamine $\mathrm{D}_{2}$ and serotonin $5-\mathrm{HT}_{2 \mathrm{~A}}$ receptors. Clozapine and olanzapine represent multiacting receptor-targeted antipsychotics, the drugs show a weak affinity to $D_{2}$ receptors and an affinity to other systems, such as the cholinergic, histaminergic, $5-\mathrm{HT}_{1 \mathrm{~A}}, 5-\mathrm{HT}_{2 \mathrm{C}}$ and others [6]. Risperidone and multiacting receptor-targeted antipsychotics share antipsychotic effects but differ from each other in the induction of neuroplastic changes mediated by the brain-derived neurotrophic factor (BDNF). After administration of risperidone, reduced production of mRNA for BDNF was found in the hippocampus and the frontal and orbital cortical regions in rats. On the other hand, the chronic administration of olanzapine increased the expression of BDNF $[29,30]$. Congruently, olanzapine induces volumetric changes in patients [31]. It is noteworthy that the $5-\mathrm{HT}_{2 \mathrm{~A}}$ antagonism itself leads to a higher production of $\mathrm{BDNF}[32,33]$ and that, conversely, $\mathrm{D}_{2}$ antagonism reduces BDNF [34]. This explains the BDNFstimulating effect of olanzapine and clozapine. Risperidone is also a strong $5-\mathrm{HT}_{2 \mathrm{~A}}$ antagonist, but due to its very high affinity to $D_{2}$ receptors its $D_{2}$-mediated suppression of BDNF may prevail. Therefore, we speculate that the difference between the 2 groups of antipsychotic, in terms of the electrical brain activity detected by LORETA, would be explained by the neuroplastic effect characteristic only for the multiacting receptor-targeted antipsychotic group. These neuroplastic changes would 
be responsible for the inhibitory effect on the medial frontal cortex documented by the increase of the theta and delta frequencies.

When comparing antipsychotic-naive patients with healthy controls, we found a general increase in slow frequencies, mainly in the temporolimbic structures, which is in agreement with existing functional findings. In patients who received clozapine and olanzapine compared with those who were antipsychotic-naive, we found the most prominent changes in the anterior cingulate and medial frontal cortex and a decrease in fast frequency activities in the occipital cortex. This could suggest a compensatory mechanism in the neurobiological substrate for schizophrenia. The absence of any differences in the patients on risperidone compared to the antipsychoticnaive schizophrenics may relate to its different pharmacodynamic mechanism.

\section{Acknowledgements}

This research was supported by grant NR8792 from the Grant Agency of the Ministry of Health, Czech Republic, and by projects 1 M0517 and VZ 0021620816 from the Ministry of Education, Youth and Sports, Czech Republic. The authors thank Craig Hampson for his linguistic assistance.

\section{References}

1 Pascual-Marqui RD, Michel CM, Lehmann D: Low resolution electromagnetic tomography: a new method for localizing electrical activity in the brain. Int J Psychophysiol 1994;18:49-65.

-2 Pascual-Marqui RD, Esslen M, Kochi K, Lehmann D: Functional imaging with lowresolution brain electromagnetic tomography (LORETA): a review. Methods Find Exp Clin Pharmacol 2002;24(suppl C):91-95.

3 Mientus S, Gallinat J, Wuebben Y, PascualMarqui RD, Mulert C, Frick K, Dorn H, Herrmann WM, Winterer G: Cortical hypoactivation during resting EEG in schizophrenics but not in depressives and schizotypal subjects as revealed by low resolution electromagnetic tomography (LORETA). Psychiatry Res 2002;116:95-111.

4 Pascual-Marqui RD, Lehmann D, Koenig T, Kochi K, Merlo MC, Hell D, Koukkou M: Low resolution brain electromagnetic tomography (LORETA) functional imaging in acute, neuroleptic-naive, first-episode, productive schizophrenia. Psychiatry Res 1999; 90:169-179.

-5 Saletu B, Anderer P, Saletu-Zyhlarz GM:EEG topography and tomography (LORETA) in the classification and evaluation of the pharmacodynamics of psychotropic drugs. Clin EEG Neurosci 2006;37:66-80.

6 Horacek J, Bubenikova-Valesova V, Kopecek M, Palenicek T, Dockery C, Mohr P, Höschl $\mathrm{C}$ : Mechanism of action of atypical antipsychotic drugs and the neurobiology of schizophrenia. CNS Drugs 2006;20:389-409.

-7 Centorrino F, Price BH, Tuttle M, Bahk WM, Hennen J, Albert MJ, Baldessarini RJ: EEG abnormalities during treatment with typical and atypical antipsychotics. Am J Psychiatry 2002;159:109-115.

LORETA, Atypical Antipsychotics and Schizophrenia
8 Gross A, Joutsiniemi SL, Rimon R, Appelberg B: Clozapine-induced QEEG changes correlate with clinical response in schizophrenic patients: a prospective, longitudinal study. Pharmacopsychiatry 2004;37:119122.

-9 Veiga H, Deslandes A, Cagy M, Fiszman A, Piedade RA, Ribeiro P: Neurocortical electrical activity tomography in chronic schizophrenics. Arq Neuropsiquiatr 2003;61:712717.

10 Galderisi S, Mucci A, Bucci P, Mignone ML, Maj M: Multilead quantitative EEG profile of clozapine in resting and vigilance-controlled conditions. Psychiatry Res 1996;67:113122.

11 Hubl D, Kleinlogel H, Frölich L, Weinandi T, Maurer K, Holstein W, Czekalla J, Dierks T: Multilead quantitative electroencephalogram profile and cognitive evoked potentials (P300) in healthy subjects after a single dose of olanzapine. Psychopharmacology (Berl) 2001;158:281-288.

12 Yoshimura M, Koenig T, Irisawa S, Isotani T, Yamada K, Kikuchi M, Okugawa G, Yagyu T, Kinoshita T, Strik W, Dierks T: A pharmacoEEG study on antipsychotic drugs in healthy volunteers. Psychopharmacology (Berl) 2007;191:995-1004.

13 World Health Organization (WHO): The ICD-10 Classification of Mental and Behavioural Disorders: Diagnostic Criteria for Research. Geneva, WHO, 1993.

14 Kubicki S, Herrmann WM, Fichte K, Freund G: Reflections on the topics: EEG frequency bands and regulation of vigilance. Pharmakopsychiatr Neuropsychopharmakol 1979; 12:237-245.

15 Holmes AP, Blair RC, Watson JD, Ford I: Nonparametric analysis of statistic images from functional mapping experiments. J Cereb Blood Flow Metab 1996;16:7-22.
6 Horacek J, Brunovsky M, Novak T, Skrdlantova L, Klirova M, Bubenikova-Valesova V, Krajca V, Tislerova B, Kopecek M, Spaniel F, Mohr P, Höschl C: Effect of low-frequency rTMS on electromagnetic tomography (LORETA) and regional brain metabolism (PET) in schizophrenia patients with auditory hallucinations. Neuropsychobiology 2007;55:132-142.

17 Frith CD: Functional brain imaging and the neuropathology of schizophrenia. Schizophr Bull 1997;23:525-527.

18 Liddle PF: Dynamic neuroimaging with PET, SPECT or fMRI. Int Rev Psychiatry 1997;9:331-337.

19 Glantz LA, Lewis DA: Decreased dendritic spine density on prefrontal cortical pyramidal neurons in schizophrenia. Arch Gen Psychiatry 2000;57:65-73.

20 Bartzokis G: Schizophrenia: breakdown in the well-regulated lifelong process of brain development and maturation. Neuropsychopharmacology 2002;27:672-683.

21 Weinberger DR, Egan MF, Bertolino A, Callicott JH, Mattay VS, Lipska BK, Berman KF, Goldberg TE: Prefrontal neurons and the genetics of schizophrenia. Biol Psychiatry 2001;50:825-844.

-22 Lahti AC, Holcomb HH, Weiler MA, Medoff DR, Frey KN, Hardin M, Tamminga CA: Clozapine but not haloperidol re-establishes normal task-activated rCBF patterns in schizophrenia within the anterior cingulate cortex. Neuropsychopharmacology 2004;29: 171-178.

23 Lahti AC, Weiler MA, Medoff DR, Tamminga CA, Holcomb HH: Functional effects of single dose first- and second-generation antipsychotic administration in subjects with schizophrenia. Psychiatry Res 2005;139:1930. 
24 McCormick L, Decker L, Nopoulos P, Ho BC, Andreasen N: Effects of atypical and typical neuroleptics on anterior cingulate volume in schizophrenia. Schizophr Res 2005;80:73-84.

-25 Yamada K, Isotani T, Irisawa S, Yoshimura M, Tajika A, Yagyu T, Saito A, Kinoshita T: EEG global field power spectrum changes after a single dose of atypical antipsychotics in healthy volunteers. Brain Topogr 2004;16: 281-285.

-26 Kopelman A, Andreasen NC, Nopoulos P: Morphology of the anterior cingulate gyrus in patients with schizophrenia: relationship to typical neuroleptic exposure. Am J Psychiatry 2005;162:1872-1878.

-27 Fallgatter AJ, Bartsch AJ, Zielasek J, Herrmann MJ: Brain electrical dysfunction of the anterior cingulate in schizophrenic patients. Psychiatry Res 2003;124:37-48.
28 Mulert C, Gallinat J, Pascual-Marqui R, Dorn H, Frick K, Schlattmann P, Mientus S, Herrmann WM, Winterer G: Reduced eventrelated current density in the anterior cingulate cortex in schizophrenia. Neuroimage 2001;13:589-600.

29 Bai O, Chlan-Fourney J, Bowen R, Keegan D, Li XM: Expression of brain-derived neurotrophic factor mRNA in rat hippocampus after treatment with antipsychotic drugs. Neurosci Res 2003;71:127-131.

30 Angelucci F, Mathe AA, Aloe L: Brainderived neurotrophic factor and tyrosine kinase receptor $\operatorname{TrkB}$ in rat brain are significantly altered after haloperidol and risperidone administration. J Neurosci Res 2000;60:783-794.

31 Okugawa G, Nobuhara K, Takase K, Saito Y, Yoshimura M, Kinoshita T: Olanzapine increases grey and white matter volumes in the caudate nucleus of patients with schizophrenia. Neuropsychobiology 2007;55:43-46.
2 Chlan-Fourney J, Ashe P, Nylen K, Juorio AV, Li XM: Differential regulation of hippocampal BDNF mRNA by typical and atypical antipsychotic administration. Brain Res 2002;954:11-20.

33 Vaidya VA, Terwilliger RM, Duman RS: Role of $5-\mathrm{HT}_{2 \mathrm{~A}}$ receptors in the stress-induced down-regulation of brain-derived neurotrophic factor expression in rat hippocampus. Neurosci Lett 1999;262:1-4.

>34 Meredith GE, Switzer RC III, Napier TC: Short-term, $\mathrm{D}_{2}$ receptor blockade induces synaptic degeneration, reduces levels of tyrosine hydroxylase and brain-derived neurotrophic factor, and enhances $\mathrm{D}_{2}$-mediated firing in the ventral pallidum. Brain Res 2004;995:14-22. 